\title{
Effect of Age on Clinical Trial Outcome in Participants with Probable Alzheimer's Disease
}

Steven D. Targum ${ }^{\mathrm{a}, *}$, Lisa Fosdick ${ }^{\mathrm{a}}$, Kristen E. Drake ${ }^{\mathrm{a}}$, Paul B. Rosenberg ${ }^{\mathrm{b}}$, Anna D. Burke ${ }^{\mathrm{c}}$, David A. Wolk ${ }^{\mathrm{d}}$, Kelly D. Foote ${ }^{\mathrm{e}}$, Wael F. Asaad ${ }^{\mathrm{f}}$, Marwan Sabbagh ${ }^{\mathrm{g}}$, Gwenn S. Smith ${ }^{\mathrm{b}}$, Andres M. Lozano ${ }^{\mathrm{h}}$ and Constantine G. Lyketsos ${ }^{\mathrm{b}}$

${ }^{\text {a }}$ Functional Neuromodulation Ltd., Minneapolis MN, USA

' $\mathrm{bemory}$ and Alzheimer's Treatment Center \& Alzheimer's Disease Research Center, Division of Geriatric Psychiatry and Neuropsychiatry, Department of Psychiatry and Behavioral Sciences, Johns Hopkins University School of Medicine, Baltimore, MD, USA

${ }^{\mathrm{c}}$ Department of Neurology, Barrow Neurological Institute, Phoenix, AZ, USA

${ }^{\mathrm{d}}$ Penn Memory Center, Department of Neurology, University of Pennsylvania, Philadelphia, PA, USA

${ }^{\mathrm{e}}$ Departments of and Neurosurgery and Neurology, University of Florida, Fixel Institute for Neurological Diseases, Gainesville, FL, USA

${ }^{\mathrm{f}}$ Department of Neurosurgery, Rhode Island Hospital and the Alpert Medical School of Brown University, Providence, RI, USA

${ }^{\mathrm{g}}$ Cleveland Clinic Lou Ruvo Center for Brain Health, Cleveland, OH, USA

${ }^{\mathrm{h}}$ Department of Surgery (Neurosurgery), University of Toronto, Toronto, ON, Canada

Accepted 18 May 2021

Pre-press 16 June 2021

\begin{abstract}
.
Background: Age may affect treatment outcome in trials of mild probable Alzheimer's disease (AD).

Objective: We examined age as a moderator of outcome in an exploratory study of deep brain stimulation targeting the fornix (DBS-f) region in participants with AD.

Methods: Forty-two participants were implanted with DBS electrodes and randomized to double-blind DBS-f stimulation ("on") or sham DBS-f ("off”) for 12 months.

Results: The intervention was safe and well tolerated. However, the selected clinical measures did not differentiate between the "on" and "off" groups in the intent to treat (ITT) population. There was a significant age by time interaction with the Alzheimer's Disease Assessment Scale; ADAS- $\operatorname{cog}-13(p=0.028)$. Six of the 12 enrolled participants $<65$ years old $(50 \%)$ markedly declined on the ADAS-cog-13 versus only $6.7 \%$ of the 30 participants $\geq 65$ years old regardless of treatment assignment $(p=0.005)$. While not significant, post-hoc analyses favored DBS-f "off" versus "on" over 12 months in the $<65$ age group but favored DBS-f "on" versus "off" in the $\geq 65$ age group on all clinical metrics. On the integrated Alzheimer's Disease rating scale (iADRS), the effect size contrasting DBS-f "on" versus "off" changed from +0.2 (favoring "off") in the $<65$ group to -0.52 (favoring "on") in the $\geq 65$ age group.

Conclusion: The findings highlight issues with subject selection in clinical trials for AD. Faster disease progression in younger $\mathrm{AD}$ participants with different $\mathrm{AD}$ sub-types may influence the results. Biomarker confirmation and genotyping to differentiate $\mathrm{AD}$ subtypes is important for future clinical trials.
\end{abstract}

Keywords: Age, Alzheimer's disease, deep brain stimulation, clinical trials, subject selection

\footnotetext{
*Correspondence to: Steven D. Targum, 505 Tremont Street, \#907, Boston MA 02116, USA. Tel.: +1 617824 0800; E-mail: sdtargum@yahoo.com.
} 


\section{INTRODUCTION}

Age of onset can be a confounding moderating variable in clinical trials of probable Alzheimer's disease (AD) because many younger, early onset $A D$ participants have a more rapid cognitive decline than later onset participants that may be associated with distinct genetic subtypes [1-5]. Using data obtained from 10 studies and 2,793 probable AD participants, Schneider and colleagues [4] reported that the younger participants had faster rates of cognitive decline than the older participants on the Alzheimer's Disease Assessment Scale (ADAS-cog) over 12-24 months $(p<0.0001)$.

In a recent study, we found that age affected the clinical outcome in study participants with probable mild AD treated with deep brain stimulation targeting the fornix (DBS-f) as the experimental condition [6]. The rationale for using DBS in AD is based upon the hypothesis that modulation of neuronal circuits may sustain or possibly even improve memory function in affected individuals [7-9]. Many investigators have described functional alterations in the interconnected cortical networks associated with memory in AD participants, particularly in areas related to the hippocampus $[10,11]$. The rationale to focus DBS on patients with early illness rather than moderate $\mathrm{AD}$ was supported by a pilot study that showed greater benefits from DBS in probable $\mathrm{AD}$ participants who were less cognitively impaired and showed less severe cerebral glucose metabolic deficits prior to the intervention [7, 12, 13]. Given this rationale, a broad age range of potential study participants (45-80) who met criteria for probable mild AD were considered eligible for this Phase 2 exploratory study. The ADAS-cog-13 and Clinical Dementia Rating Scale (CDR) results failed to differentiate between AD participants assigned to DBS-f "on" (stimulation) or "off" (sham) after 12 months of blinded treatment although the FDG-PET imaging findings revealed that DBS-f "on" stimulation increased metabolic function relative to the sham treatment group [6, 14, 15]. There was an unusually high percentage of younger probable AD participants in this small study that may have impeded signal detection. Although less than $4 \%$ of the AD population are reported to develop the disease before the age of 65,12 of the 42 enrolled participants $(28.6 \%)$ in this study were $<65$ years old $[6,16,17]$. A post-hoc multivariate regression analysis revealed a significant age interaction with time and experimental condition on the ADAS- $\operatorname{cog}-13(\beta=-0.41$;
SE $0.18 ; p=0.028)$. Participants $<65$ years old had greater cognitive decline and lower pre-treatment glucose metabolism in temporal and parietal cortices than the older participants regardless of treatment assignment [6].

In our initial reports of this study, we described the safety and tolerability of the intervention as well as the ADAS-cog and CDR results $[6,18,19]$. In this post-hoc analysis, we report additional clinical results from two secondary outcome measures, the ADCS-Activities of Daily Living scale (ADCSADL-23) and the integrated Alzheimer's Disease Rating Scale (iADRS) [20-23]. The iADRS provides a composite score that combines the cognitive measures of the ADAS-cog-13 with the instrumental items of the ADCS-ADL-23 [14, 20, 21]. In two recent clinical trials, the iADRS was chosen as the primary efficacy measure and was able to demonstrate a statistically significant slowing of clinical decline favoring solanezumab over placebo in one study, and donanemab over placebo in the other study $[22,23]$. Our post-hoc analysis of the iADRS in the ADvance study confirms that age was a pivotal moderating factor affecting signal detection and offers data that may be useful for the design of future AD trials.

\section{MATERIALS AND METHODS}

Data for this report were derived from the phase II AD study ADvance: A Twelve Month Double-blind Randomized Controlled Feasibility Study to Evaluate the Safety, Efficacy and Tolerability of Deep Brain Stimulation of the Fornix (DBS-f) in Participants with Mild Probable Alzheimer's Disease sponsored by Functional Neuromodulation LLC. The trial was overseen by the Food and Drug Administration (USA) and by Health Canada and registered with clinicaltrials.gov (NCT01608061). Seven clinical trial sites located in the United States and Canada participated in the study that was conducted between May 2012 and June 2015 (last patient enrolled in March 2014). The study was conducted in compliance with local Institutional Review Board (IRB) informed consent regulations and International Conference on Harmonization (ICH) for Good Clinical Practice (GCP) Guidelines.

All potentially eligible participants personally provided informed consent and signed an IRB approved consent form at the screening visit with input from identified caregiver/informants. Participants and caregivers (informants) signed a second consent form at the baseline visit prior to DBS-f implantation. 


\section{Study eligibility criteria}

Eligible participants were men or women between the ages of 45 and 80 years living at home with a reliable informant, who had a General Medical Health Rating $\geq 3$ (good or excellent), and who met criteria for probable AD according to the National Institute of Aging/Alzheimer's Association criteria [24]. An essential component of eligibility was a narrative documentation of memory complaints affecting behavior or daily function for at least a year, evidence of functional decline over the past year, and a stable dose of a cholinesterase inhibitor (donepezil, galantamine, or rivastigmine) for at least 60 days prior to signing the informed consent. In addition, eligible participants had a Clinical Dementia Rating Scale (CDR) global rating of 0.5 or 1.0, and an Alzheimer's Disease Assessment Scale-cognitive component (ADAS-cog11) score of 12-24 (inclusive) with a score $\geq 4$ on ADAS-cog item 1 (immediate recall) at both the screening and baseline visits $[14,15,25]$.

The exclusion criteria included scores of $\geq 11$ on the Young Mania Rating Scale, $>10$ on the Cornell Scale for Depression and Dementia, $>4$ on the modified Hachinski ischemia score, and $\geq 10$ on the Neuropsychiatric Inventory (NPI) total score (or $\geq 4$ in any domain except apathy) at the screening visit $[14,15,25-28]$. Potential participants were excluded if they replied "yes" to "suicidal ideation" or "yes" to any items in the suicidal behavior section with reference to the three-month period prior to screening on the Columbia Suicide Severity Rating Scale (C-SSRS) or had attempted suicide within the past 2 years [29]. Participants had to be considered a good surgical candidate by the neurosurgeon, free of contraindications for surgery or exclusions for magnetic resonance (MR) imaging (pacemakers, metal implanted in the body) or positron emission tomography (PET) scanning (e.g., insulin-dependent diabetes). Detailed inclusion/exclusion criteria for the ADvance study have been previously published [30].

The study protocol did not require $A P O E$ or CSF biomarkers as part of the study eligibility criteria. The subject eligibility process included pre-screening by both the trial site and a 3-member siteindependent enrollment review committee (ERC) composed of psychiatrists, neurologists, and neurosurgeons who examined eligibility documentation for every potential study participant. The ERC reviewed all documentation related to participant eligibility including the documentation of functional decline in the past year. An approval to proceed toward randomization and implantation required the unanimous decision of the ERC.

\section{Study design}

Figure 1 provides a schematic outline of the ADvance design. The 12-month DBS-f “on" (stimulation) or "off" (sham treatment) 1:1 randomization period following implantation was followed by a 12-month open-label extension for all participants. A more detailed description of the study methods, including the neuroimaging methods and the standardization of the surgical procedures have been published elsewhere $[6,18,30]$.

A CRO (clinical research organization) statistician generated the 1:1 random allocation sequence that was stratified by the site using SAS according to the CRO's standard operating procedures. Only the statistician knew the block sizes. A sponsor clinical engineer and an unblinded site technician carried out the randomization and recorded the blinded code number at the site. All other trial site staff, study participants, families, CRO, and sponsor personnel were blinded to the randomization allocation throughout the study.

\section{DBS neurosurgical implantation}

The target site for neurosurgical implantation of the DBS electrodes for AD was just anterior and in juxtaposition to the post commissural fornix (DBS-f). The fornix, a critical part of the Papez circuit, was chosen for DBS in mild AD because it is a major inflow and output pathway from the hippocampus and medial temporal lobe $[7,18]$. Furthermore, there is accumulating evidence from pre-clinical and human imaging studies suggesting that the fornix is involved early in cognitive decline [8, 9]. A Model 37601 Activa PC pulse generator battery and Model 3387 Leads with Model 37085 extensions (supplied by Medtronic, Inc.) was implanted in all participants who continued to meet randomization criteria at the baseline visit. A more detailed description of the neurosurgical procedure and safety outcomes are provided elsewhere $[7,18]$.

\section{Neuroimaging}

All eligible participants underwent 1.5TMR scans at baseline and 12 months to obtain a structural image and $\left[{ }^{18} \mathrm{~F}\right]$-2-deoxy-2-fluoro-D-glucose PET 


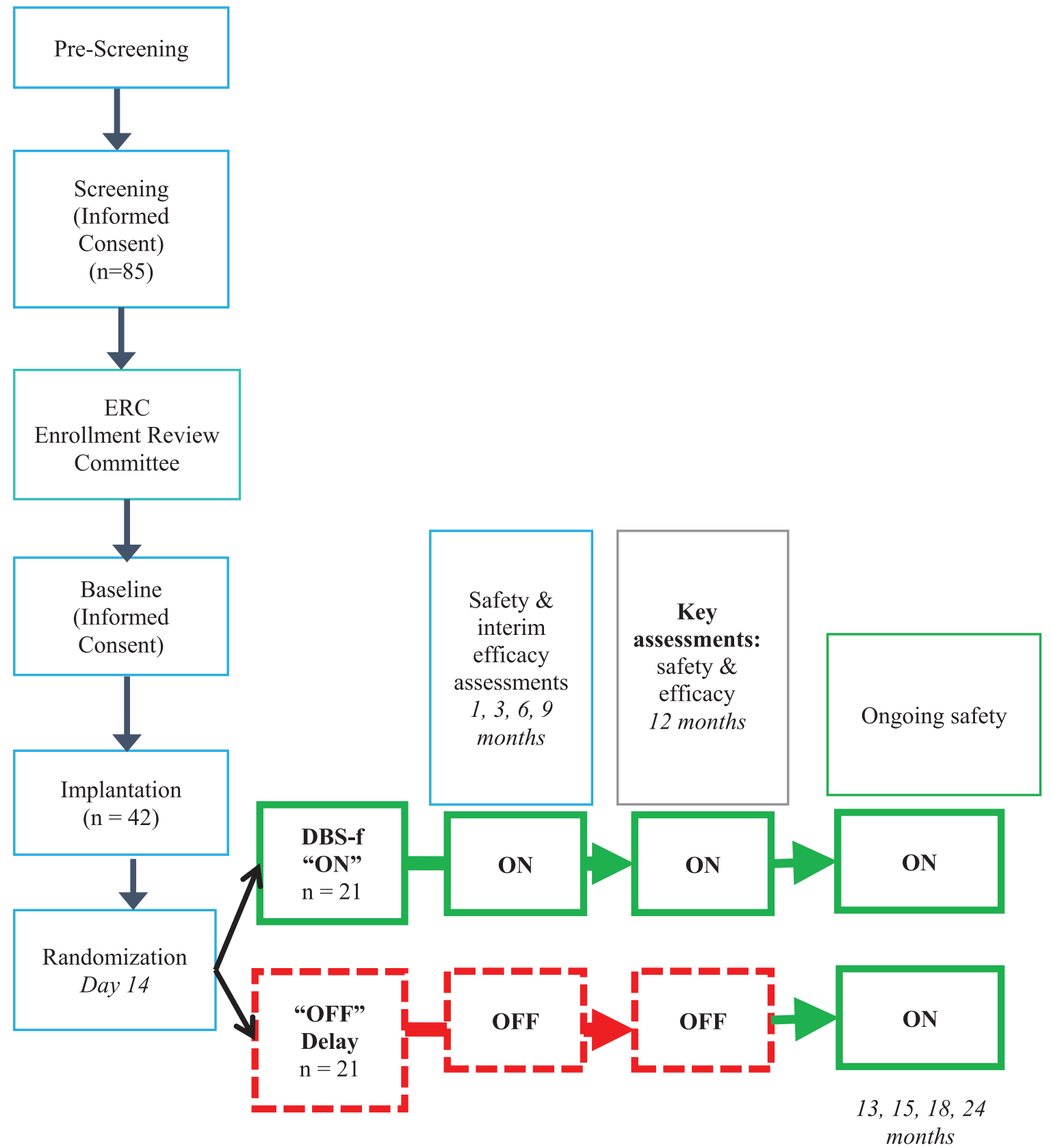

Fig. 1. Schematic of Advance AD study design (CONSORT).

(FDG-PET) at baseline and at 1, 6, and 12 months after surgery with the stimulators maintained 'on' in the active group and 'off' in the sham group during the PET scans [6].

\section{Clinical outcome measures}

ADvance was a feasibility study in which the primary objective was to evaluate the safety and tolerability of DBS-f in participants with probable mild AD by assessing device and/or therapy related adverse events after 12 months. The secondary objective was to provide a preliminary estimate of the treatment effect size on selected clinical psychometric measures and neuroimaging outcomes at 12 months post-randomization.

The primary outcomes were the ADAS-Cog-13 and CDR sum of boxes (CDR-SB) at 12 months 
[14, 15, 25]. The Alzheimer's Disease Cooperative Study Activities of Daily Living scale (ACDS-ADL23) scale was a secondary outcome [20]. We added the integrated Alzheimer's Disease Rating Scale (iADRS) in this post-hoc analysis [21, 22]. The iADRS is a composite of the ADAS-cog-13 and instrumental items of the ADCS-ADL (iADL) scores.

\section{Statistical analyses}

The study objectives did not include formal tests or hypotheses as it was not powered to detect a statistically significant difference between treatment arms. All analyses were initially performed on the intention-to-treat (ITT) population that represented all participants who were randomized. In a post-hoc analysis, the ITT population was divided into two age cohorts made up of participants $<65$ years old and $\geq 65$ years old. Descriptive statistics compared treatment groups on baseline variables. Betweengroup comparisons for change from baseline were made using ANOVA or $t$-tests and 2-sided $p$-values at each time point. Cohen's d effect size (ES) was calculated as the expected difference in change at 12 months divided by the pooled standard deviation [31]. All analyses were performed with SAS software, version 9.3 or greater.

\section{RESULTS}

Adherence with study procedures was excellent throughout the study. It was possible to obtain both baseline and 12-month (endpoint) ADAS-cog13 scores on all 42 participants and CDR-SB and ADCS-ADL-23 scores on 41 participants. The primary measures (ADAS-cog-13 and CDR-SB) did not differentiate between the DBS-f "on" and "off" groups after 12 months of double-blind treatment. A key post-hoc finding was that participants $<65$ years old had a more rapid cognitive decline and lower glucose metabolism in temporal and parietal cortices than the older participants regardless of treatment assignment [6].

\section{Demographic and baseline data}

Participants ranged in age from 48 to 80 years old. Twelve participants were $<65$ years of age $(28.6 \%$ of

Table 1

Characteristics of Randomized Participants in the ADvance DBS-f Study of Mild AD (stratified by age cohorts)

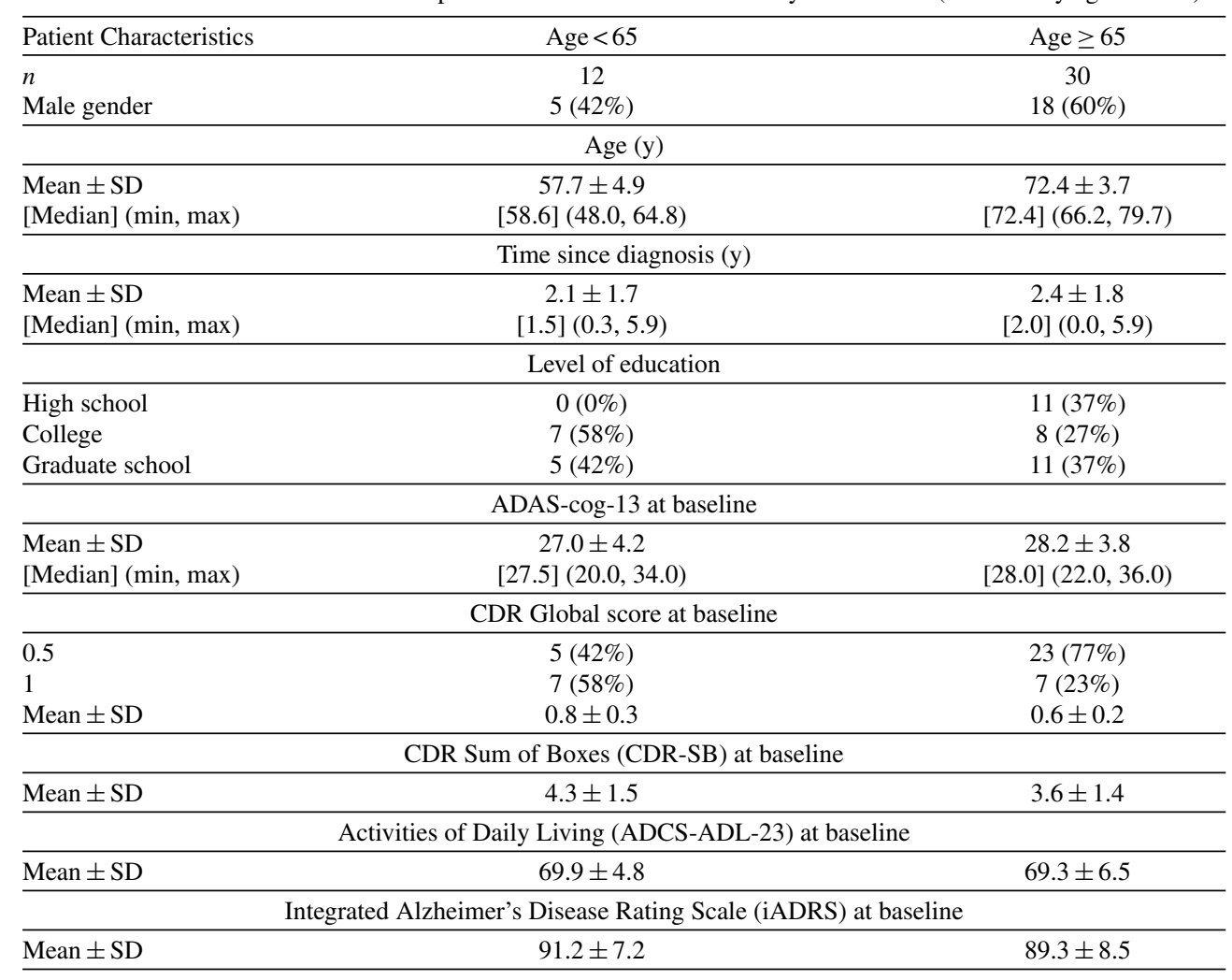


the study population). All randomized participants had a documented history of behavioral and/or daily functional difficulties attributed to memory complaints for at least one year and had been taking cholinesterase inhibitor medication for at least 60 days prior to signing the informed consent. All participants were diagnosed with mild probable $\mathrm{AD}$ and had global CDR scores of 0.5 or 1.0. The mean time since the formal diagnosis of probable AD had been made by a physician was approximately two years, although some participants had been diagnosed nearly 6 years before the start of the study. The total ADAS-cog-11 scores for the 42 randomized participants at the baseline visit ranged from 12 to 22 (mean $=16.9 \pm 2.9 \mathrm{SD})$.

Table 1 lists demographic characteristics and baseline clinical scores for the 42 randomized participants stratified by age $(<65$ years old versus $\geq 65$ years old).

Twenty-eight participants (67\%) had CDR global scores of 0.5 and 14 participants $(33 \%)$ had CDR global scores of 1.0 at the baseline visit. The mean CDR-SB score was $3.9 \pm 1.7$ with a wide score range from 1.0 to 8.0 at the baseline visit. There were no significant differences between the $<65$ years old and $\geq 65$ years old participants on baseline mean ADAS, CDR, ADCS-ADL, or iADRS. The ADAS-cog-13 scores were correlated with the CDR-SB scores at baseline $(r=0.459)$ and at 12 months $(r=0.676)$. Similarly, the iADRS scores were highly correlated with the CDR-SB score at baseline $(r=-0.735)$ and at 12 months $(r=-0.859)$ and the correlation did not differ between the age cohorts.

\section{Clinical outcomes from the ITT population}

The study's primary report was published elsewhere and can be summarized as follows: the mean change scores of the primary outcomes (ADAScog-13 and CDR-SB) revealed progressive cognitive decline over 12 months consistent with mild AD but did not distinguish between the DBS-f "on" and "off" treatment groups in the ITT population [6].

\section{Post-hoc analyses}

As previously reported [6], a post-hoc multivariate regression analysis of the ITT population revealed a significant time by age interaction with ADAS-cog13 outcomes (beta $=-0.41$; SE $0.18 ; p=0.028$ ): the 12 participants $<65$ years old had greater cognitive decline and decreased glucose metabolism over 12 months regardless of treatment assignment than the 30 older participants [6].

Figure 2 displays mean observed score differences between the DBS-f "on" and "off" groups on the ADAS-cog-13 and CDR-SB scores stratified by 5 -year age intervals. As shown by this sensitivity analysis, DBS-f "on" assigned participants $<65$ years old did worse than DBS-f "off" participants on both the ADAS-cog-13 and CDR-SB, whereas DBS$f$ "on" participants $\geq 65$ years old did better than the "off" group.

Table 2 compares mean change scores from baseline to 12 months for the clinical metrics in the ITT population and the two post-hoc defined age cohorts. As shown, the DBS-f "on" group did significantly worse than the "off" group on all clinical measures in the $<65$ age cohort. Cohen' $s$ effect size estimates (ES) favored DBS-f "off" versus "on" in the $<65$ age cohort on all of the outcomes. The mean iADRS change score difference between the DBS-f "on" and "off" groups was 0.4 in the ITT population but increased to a 21.4-point difference favoring the DBS-f "off" group in the $<65$ age cohort $(\mathrm{ES}=1.41$ ).

In contrast, the DBS-f "on" group did substantially better than the DBS-f "off" group in the $\geq 65$ age cohort. The ES calculation favored DBS-f "on" in the $\geq 65$ age cohort on all of the clinical metrics. Although not statistically significant, the ES for the ADAS-cog-13 favoring the DBS-f "on" treatment group increased from 0.00 in the entire ITT population to 0.58 in the 30 participants $\geq 65$ years old, and the ES for the CDR-SB increased from 0.09 to 0.52 .

In the $\geq 65$ age cohort, the mean iADRS change score increased to a 9.3-point difference favoring the DBS-f "on" group versus the DBS-f "off" group. The ES for the iADRS improved from +0.02 in the ITT population to -0.52 favoring DBS-f "on" in the $\geq 65$ age cohort.

Figure 3 displays the trajectory of the mean iADRS scores in the two age cohorts.

\section{Individual participant analyses}

Figure 4 displays individual ADAS-cog-13 score changes recorded between the baseline and 12 -month visits for each of the 42 enrolled participants. Notably, 8 participants had greater than a 20-point ADAS$\operatorname{cog}-13$ score worsening over 12 months. Six of the "outlier" participants were in the $<65$ age cohort (representing $50 \%$ of the younger cohort) in contrast to only 2 of the 30 participants $(6.7 \%)$ in the $\geq 65$ 

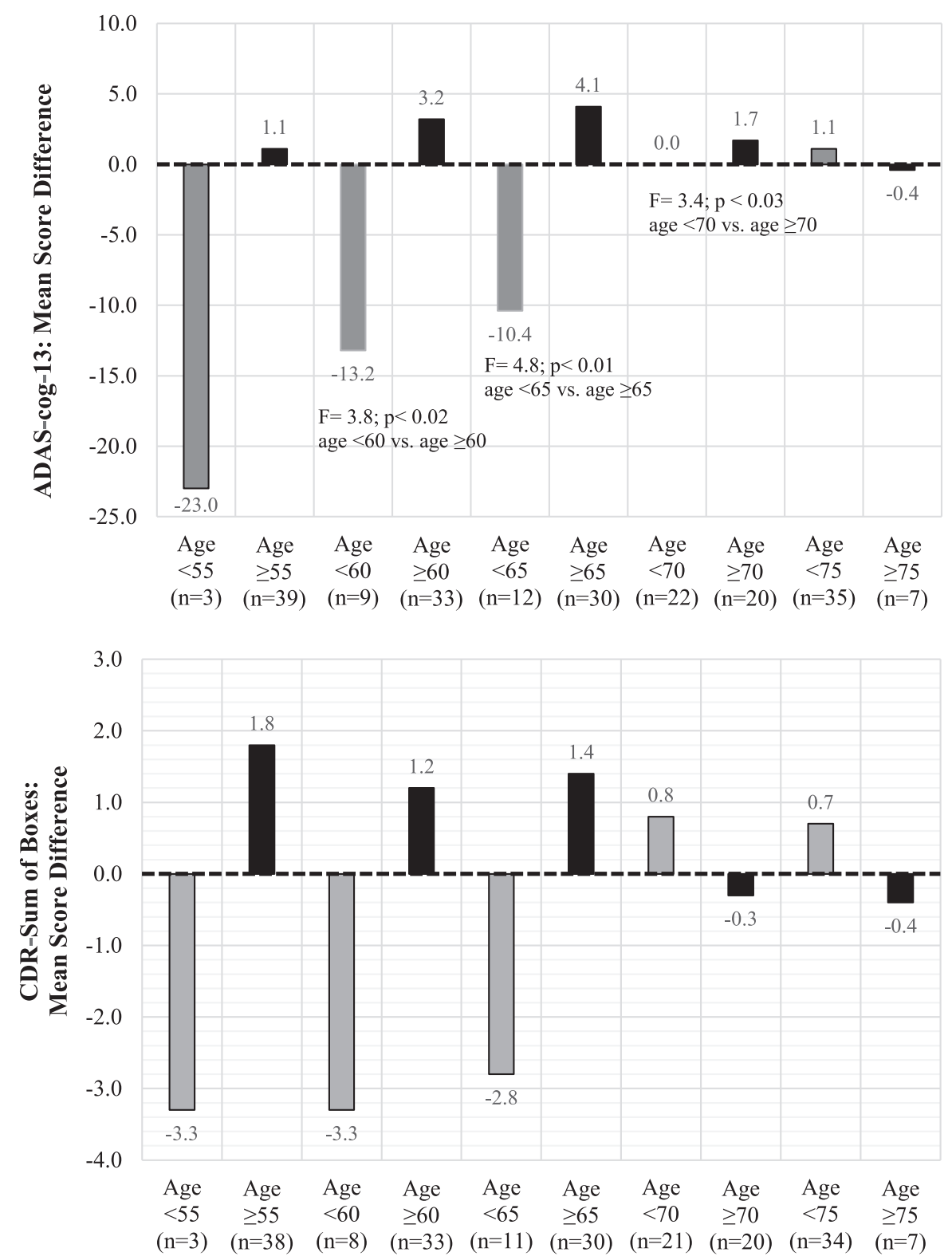

Fig. 2. ADAS-cog-13 and CDR-SB mean score differences between DBS-f "on" and "off" groups from baseline to 12 months stratified by different age cutoffs*. *Each bar represents the mean score difference between the DBS "on" versus DBS "off" participants in each age category. Positive mean score differences indicate that the DBS-f "on" group had less decline than the DBS-f "off" group whereas negative mean score differences indicate that the DBS-f "on" group had more decline.

age cohort $\left(\chi^{2}=7.82 ; \mathrm{df}=1 ; p=0.005\right)$. The presence of 6 outliers in the $<65$ age cohort may explain the marked differences observed between the "on" and "off" groups between the younger and older age cohorts and warrants further examination of the younger patient cohort.

Table 3 lists the available ADAS-cog-13 and CDR-SB scores for each of the 12 participants in the $<65$ years age cohort at each study visit. The
ADAS-cog-13 trajectories for the $<65$ years age cohort are displayed in Fig. 5. Four of the 6 younger participants who had $\geq 20$-point score change (worsening) on the ADAS-cog-13 were randomly assigned to the DBS-f "on" group and the other 2 were assigned to the "off" group.

As noted above, the ADAS-cog-13 and CDR-SB scores were correlated at baseline and 12-months ( $r=0.459$ and $r=0.676$ respectively). Further, the 
Table 2

Outcome score changes from baseline to 12 months stratified by age cohorts

\begin{tabular}{|c|c|c|c|c|c|c|}
\hline & \multicolumn{2}{|c|}{$\begin{array}{c}\text { ITT } \\
\text { population }\end{array}$} & \multicolumn{2}{|c|}{$\begin{array}{c}\text { Participants } \\
\geq 65 \text { years old } \\
\end{array}$} & \multicolumn{2}{|c|}{$\begin{array}{c}\text { Participants } \\
<65 \text { years old } \\
\end{array}$} \\
\hline & DBS-f "off" & DBS-f “on” & DBS-f "off" & DBS-f "on" & DBS-f "off" & DBS-f "on" \\
\hline Enrolled $(n)$ & 21 & 21 & 15 & 15 & 6 & 6 \\
\hline \multicolumn{7}{|l|}{ ADAS-cog-13 } \\
\hline Mean change $\pm \mathrm{SD}$ & $8.0 \pm 1.9$ & $8.0 \pm 2.2$ & $7.8 \pm 2.1$ & $3.7 \pm 1.5$ & $8.3 \pm 4.5$ & $18.7 \pm 4.1$ \\
\hline Difference \pm SD & & $0.0 \pm 2.9$ & & $4.1 \pm 2.6$ & & $-10.3 \pm 6.1$ \\
\hline$p$ & & $\mathrm{~ns}$ & & 0.12 & & 0.12 \\
\hline Cohen's d (ES) & & 0.00 & & 0.58 & & -0.97 \\
\hline \multicolumn{7}{|l|}{ CDR-SB } \\
\hline Mean change $\pm \mathrm{SD}$ & $2.4 \pm 0.4$ & $2.7 \pm 0.7$ & $3.5 \pm 0.9$ & $2.1 \pm 0.5$ & $0.5 \pm 0.3$ & $3.4 \pm 0.8$ \\
\hline Difference \pm SD & & $-0.3 \pm 0.8$ & & $1.4 \pm 1.0$ & & $-2.9 \pm 0.8$ \\
\hline$p$ & & ns & & 0.17 & & 0.006 \\
\hline Cohen's d (ES) & & 0.09 & & 0.52 & & -2.16 \\
\hline \multicolumn{7}{|l|}{ CDR-Global } \\
\hline Mean change \pm SD & $0.4 \pm 0.1$ & $0.4 \pm 0.1$ & $0.5 \pm 0.1$ & $0.4 \pm 0.1$ & $0.1 \pm 0.1$ & $0.6 \pm 0.2$ \\
\hline Difference \pm SD & & $0.0 \pm 0.1$ & & $0.1 \pm 0.2$ & & $-0.5 \pm 0.2$ \\
\hline$p$ & & $\mathrm{~ns}$ & & 0.38 & & 0.02 \\
\hline Cohen's d (ES) & & -0.11 & & 0.32 & & -1.63 \\
\hline \multicolumn{7}{|l|}{ ADCS-ADL-23 } \\
\hline Mean change $\pm \mathrm{SD}$ & $-9.8 \pm 2.9$ & $-9.5 \pm 1.5$ & $-12.0 \pm 3.6$ & $-7.9 \pm 1.8$ & $-3.2 \pm 3.1$ & $-13.3 \pm 2.3$ \\
\hline Difference \pm SD & & $0.3 \pm 3.2$ & & $4.1 \pm 4.0$ & & $10.1 \pm 3.8$ \\
\hline$p$ & & $\mathrm{~ns}$ & & 0.32 & & 0.02 \\
\hline Cohen's d (ES) & & -0.03 & & -0.37 & & 1.63 \\
\hline \multicolumn{7}{|l|}{ iADRS } \\
\hline Mean change \pm SD & $-15.7 \pm 4.0$ & $-16.1 \pm 3.0$ & $-17.3 \pm 5.9$ & $-8.0 \pm 2.4$ & $-8.4 \pm 7.0$ & $-29.8 \pm 6.0$ \\
\hline Difference $\pm S D$ & & $0.4 \pm 5.0$ & & $9.3 \pm 6.4$ & & $-21.4 \pm 9.2$ \\
\hline$p$ & & ns & & 0.16 & & 0.04 \\
\hline Cohen's d (ES) & & 0.02 & & -0.52 & & 1.41 \\
\hline
\end{tabular}

Positive mean change scores indicate worsening for the ADAS-cog-13, CDR-SB, and CDR-Global scores, whereas negative mean change scores indicate worsening for the ADCS-ADL-23 and the iADRS. A positive mean difference between the assigned treatment groups indicates that the DBS-f "on" group had less decline than the "off" group over 12 months on that metric, whereas a negative mean difference between the groups indicates that the DBS “on" group has had more decline than the "off" group. Students' $t$ tests were used to calculate the $p$ value. Positive Cohen's d (effect size) favors DBS-f “on” group for ADAS-cog-13, CDR-SB, and CDR-Global; negative effect size favors DBS-f "on" group for ADCS-ADL-23 and iADRS.

magnitude of score changes over 12 months between the ADAS-cog-13 and CDR-SB were also correlated $(r=0.463$ for the ITT population). Therefore, it is noteworthy that the sequential visit scores for participants 3 and 9 revealed marked progressive worsening on the ADAS-cog-13 score but no change at all on the CDR-SB during the course of the study (Table 3 ). The ADCS-ADL-23 and iADRS scores progressed similarly to the ADAS-cog-13 in both age cohorts since the composite score is based upon these instruments.

\section{DISCUSSION}

We conducted a pilot study of deep brain stimulation targeting the fornix (DBS-f) in 42 participants with mild probable AD. Given the exploratory nature of the study, participants as young as 45 years old were eligible to participate provided they met study eligibility criteria. As a result, the study enrolled a disproportionately high number of participants who were $<65$ years old $(28.6 \%)$ relative to the $<4 \%$ that is reported in the $\mathrm{AD}$ population at large $[16,17]$. The study achieved its primary objectives in demonstrating that DBS-f treatment in elderly adults with cognitive decline is both feasible and safe. However, none of the planned secondary clinical efficacy outcomes differentiated between the DBS-f "on" (stimulation) or "off" (sham) groups in the ITT population over the 12-months of double-blind treatment. As reported in this post-hoc analysis, age was a moderating factor that affected all study outcomes. The findings suggest that age was a proxy for the underlying heterogeneity often seen in younger $A D$ participants.

In the cohort $\geq 65$ years old $(n=30)$, all of the clinical metrics and glucose metabolism measures favored DBS-f "on" treatment over the DBS-f "off" sham treatment after 12 months, although the difference 

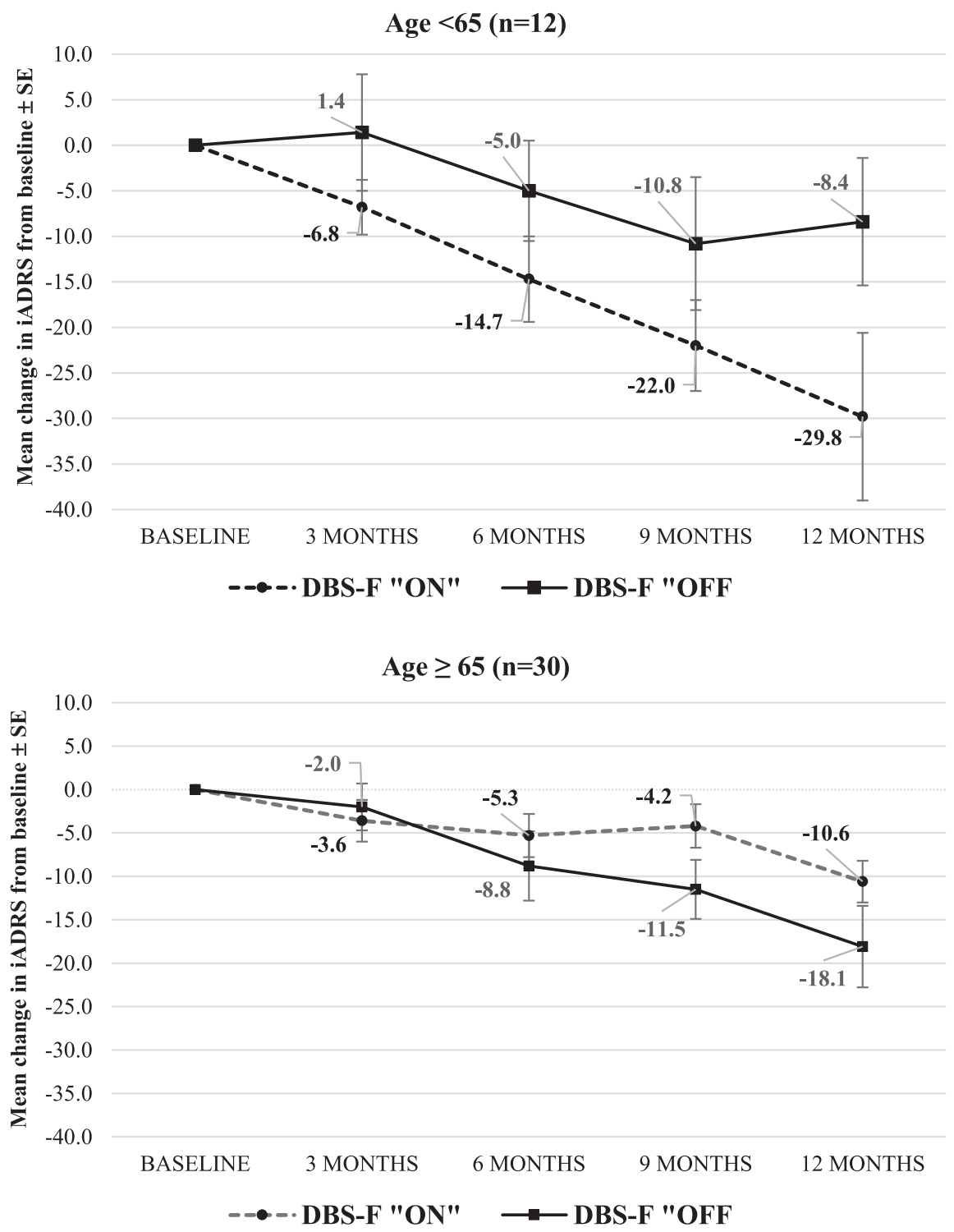

Fig. 3. Change in iADRS from baseline to month 12 in ADvance 1 study. iADRS is the integrated Alzheimer's Disease Rating Scale; negative mean change. scores indicate worsening from baseline.

did not reach statistical significance [6]. The study was not powered to show statistically significant differences between the treatment groups. However, the effect size (ES) calculations favored DBS-f "on" versus "off" in the age cohort $\geq 65$ years old and improved on other clinical metrics relative to the ITT population (Table 2). Conversely, the younger participants $<65$ years old in the DBS-f "on" group did significantly worse than the "off" group on the CDR measures, ADCS-ADL-23, and iADRS.

We added the iADRS for this present post-hoc analysis. The EXPEDITION 3 study of solanezumab used the mean change score of the iADRS as the primary efficacy measure in an 80 -week double-blind study that enrolled over 2000 participants with mild AD [22]. Over 80 weeks, the iADRS score worsened between 12-15 points from baseline in each group with a 1.7-point mean change score difference favoring solanezumab over placebo at the endpoint $(p=0.05)$. The iADRS was also the primary efficacy measure in the TRAILBLAZER-ALZ trial of donanemab that enrolled 257 AD participants [23]. After 76 weeks, the mean change score difference of the iADRS was 3.2 points favoring donanemab over placebo $(p=0.04)$. In this much smaller ADvance study (42 AD participants), the mean change score 


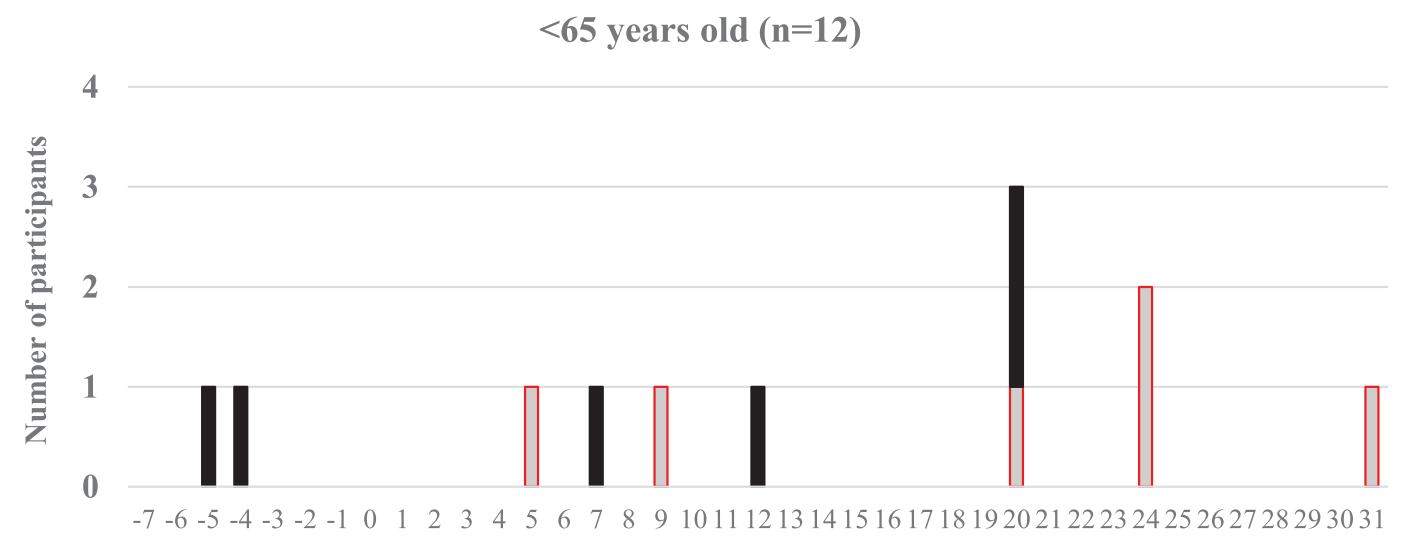

Change in ADAS-cog-13 score

$\square$ DBS-f "on" 口DBS-f "off"

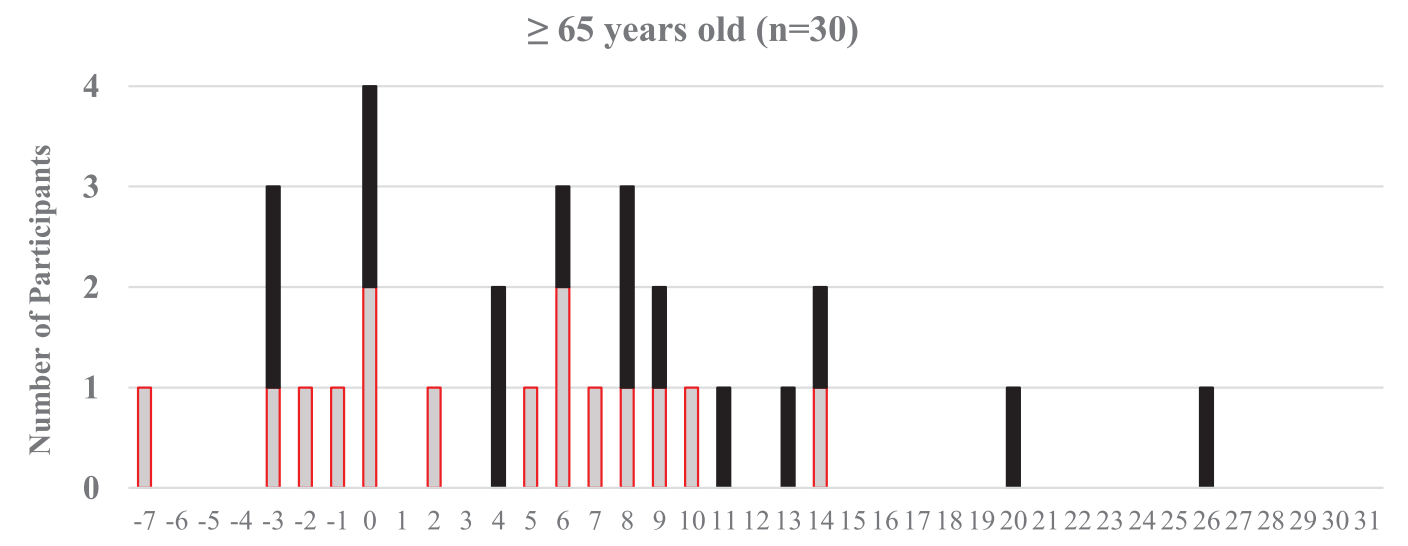

Change in ADAS-cog-13 score

口DBS-f "on" 口DBS-f "off"

Fig. 4. Distribution of ADAS-cog-13 score changes from baseline to 12 months. Negative ADAS-cog-13 change scores for each participant reflect improvement from baseline whereas positive change scores reflect progressive cognitive worsening from baseline.

difference of the iADRS after 52 weeks was 9.3 points favoring DBS-f "on" versus "off" in the $\geq 65$ age cohort (ES $=-0.52)$ but 21.4 points favoring the "off" group in the $<65$ age cohort ( $\mathrm{ES}=1.41)$.

Eight participants in this study had marked worsening of the ADAS-cog-13 score over 12 months that exceeds the progression typically seen in mild $A D$ $[4,21]$. Six of these participants were $<65$ years old ( $50 \%$ of the age $<65$ cohort) in contrast to only 2 of the 30 participants $(6.7 \%)$ in the older age cohort $(p=0.005)$. Four of the 6 younger rapidly declining participants were randomly assigned to DBS-f "on" (Table 3). It is possible that the DBS-f stimulation exacerbated the rapid cognitive decline in these younger participants, although the variability of some individual participant ADAS-cog-13 and CDR-SB responses as displayed in Table 3 suggest otherwise. It is more likely that older participants $(\geq 65$ years old) were less impaired than the younger AD participants who had different, more aggressive subtypes of $\mathrm{AD}$ than the older cohort or competing cognitive diseases that influenced their rapid decline. It is noteworthy that the pre-operative PET scans of the participants $<65$ years old revealed significantly lower glucose metabolism than the older participants in both temporal and parietal areas (middle temporal gyrus, inferior parietal lobule, precuneus; -6 to $-11 \%$ decrease; $p<0.05$ ) [6].

The observed outcome differences noted between the younger and older $\mathrm{AD}$ participants may be related 
Table 3

Trajectory of ADAS-cog-13 and CDR-SB scores in AD participants $<65$ years old

\begin{tabular}{|c|c|c|c|c|c|c|c|c|c|c|c|c|}
\hline Patient & 1 on & 2 on & 3 on & 4 on & 5 on & 6 on & 7 off & 8 off & 9 off & 10 off & 11 off & $12 \mathrm{off}$ \\
\hline age & 51 & 57 & 58 & 59 & 61 & 64 & 48 & 52 & 57 & 58 & 59 & 62 \\
\hline \multirow[t]{2}{*}{$\operatorname{sex}$} & $\mathrm{m}$ & $\mathrm{f}$ & $\mathrm{f}$ & $\mathrm{f}$ & $\mathrm{m}$ & $\mathrm{f}$ & $\mathrm{m}$ & $\mathrm{f}$ & $\mathrm{f}$ & $\mathrm{f}$ & $\mathrm{m}$ & $\mathrm{m}$ \\
\hline & \multicolumn{12}{|c|}{ ADAS-cog-13 scores } \\
\hline Baseline & 24 & 34 & 27 & 28 & 25 & 30 & 29 & 27 & 30 & 20 & 20 & 30 \\
\hline 1 month & 44 & 38 & 32 & 28 & 26 & 35 & 15 & 35 & 29 & 22 & 18 & 38 \\
\hline 3 months & 35 & 44 & 30 & 29 & 25 & 39 & 14 & 41 & 27 & 12 & 15 & 37 \\
\hline 6 months & 43 & 54 & 37 & 27 & 28 & 42 & 26 & 44 & 36 & 21 & 15 & 35 \\
\hline 9 months & 49 & 49 & 43 & 27 & 26 & 52 & 32 & 47 & 42 & 26 & 16 & 39 \\
\hline 12 months & 55 & 54 & 51 & 36 & 30 & 54 & 25 & 47 & 50 & 27 & 15 & 42 \\
\hline \multirow[t]{2}{*}{$\Delta$ baseline- 12 months } & 31 & 20 & 24 & 8 & 5 & 24 & -4 & 20 & 20 & 7 & -5 & 12 \\
\hline & \multicolumn{12}{|c|}{ CDR-SB scores } \\
\hline Baseline & 3.5 & 6.5 & 5 & 3 & 5 & 7 & 4.5 & 4.5 & 4.5 & 1.5 & 3 & 4 \\
\hline 3 months & 5 & 4.5 & 5 & 4 & 4.5 & 9 & 4 & 4.5 & 8 & 1 & 2.5 & 4 \\
\hline 6 months & 5.5 & 6.5 & 5 & 5 & 5.5 & 11 & 4.5 & 6 & 4 & 0.5 & 1 & 4.5 \\
\hline 9 months & 8 & 9 & 5 & 5 & 5.5 & 10 & 4.5 & 7 & 6 & 2 & 2.5 & 5 \\
\hline 12 months & 9 & 9 & & 6 & 5.5 & 12 & 5 & 6 & 4.5 & 2 & 2.5 & 5 \\
\hline$\Delta$ baseline- 12 months & 5.5 & 2.5 & $\mathbf{0 . 0 ^ { * }}$ & 3.0 & 0.5 & 5.0 & 0.5 & 1.5 & 0.0 & 0.5 & -0.5 & 1.0 \\
\hline
\end{tabular}

The designation of "on" indicates that the patient was assigned to DBS-f stimulation treatment whereas "off" indicates that the patient was assigned to sham treatment after the surgical implant. $\Delta$ baseline-12 months reflects score change from baseline to 12 months where positive scores reflect cognitive and/or functional worsening. ${ }^{*}$ Last observation carried forward from CDR-SB assessment at 9 months.

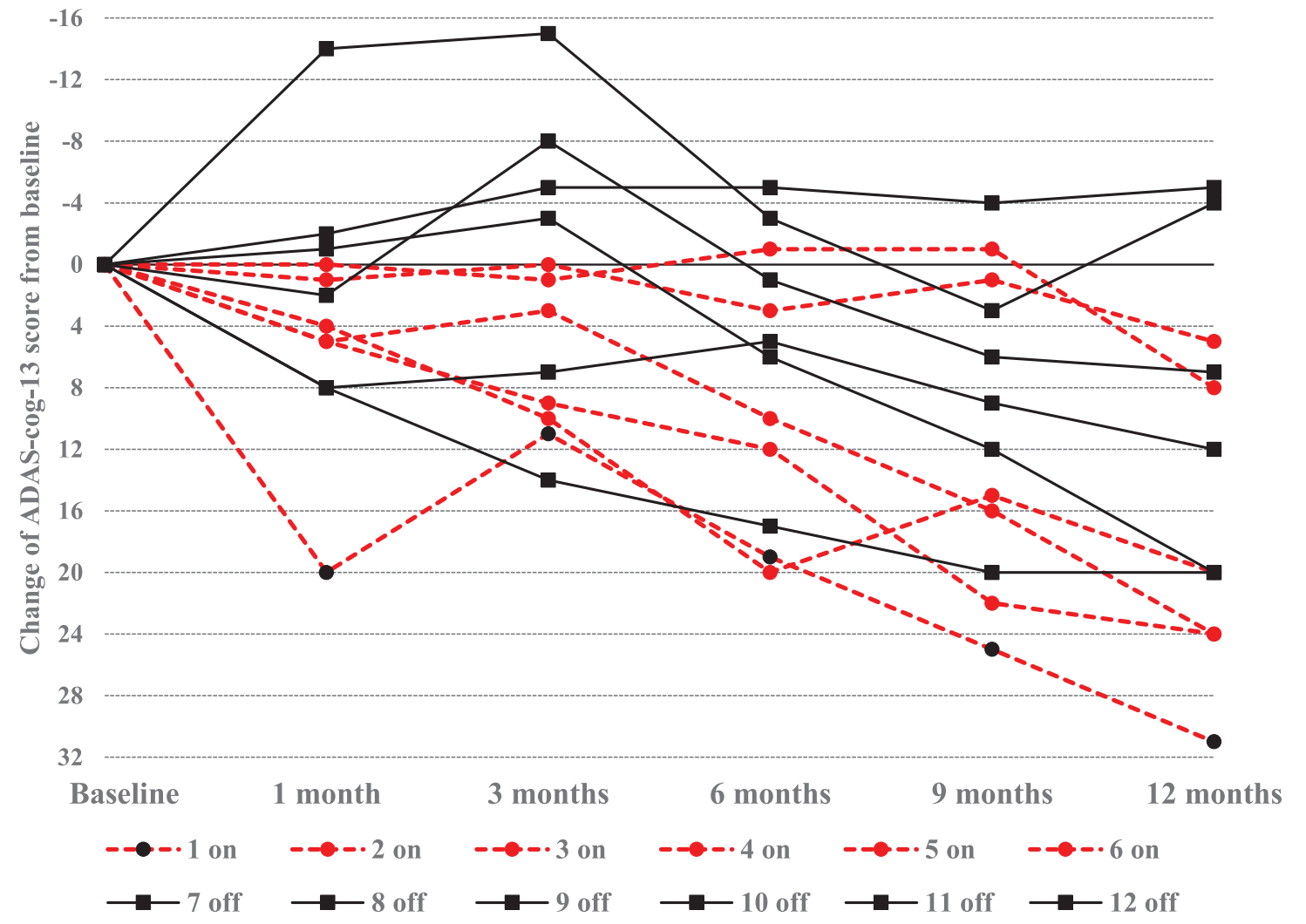

Fig. 5. Trajectory of ADAS-cog-13 score changes in AD participants $<65$ years old. Graphic reflects individual ADAS-cog-13 score changes from baseline in the DBS-f "on" and DBS-f "off" assigned participants $<65$ years old; Negative change scores indicate improvement whereas positive scores indicate worsening from baseline. 
to genetic subtypes of $\mathrm{AD}$ that cause greater brain atrophy, metabolic deficits, and a more malignant course in younger participants [1-4, 32-34]. Three genes have been associated with early onset $\mathrm{AD}$ (amyloid precursor protein and the presenilins 1 and 2 ) and presenilin 1 has been identified in frontotemporal dementia, which lacks amyloid pathology [33]. Although we did not do genetic testing in this study, participants were excluded if it was known that there was a family history of familial autosomal dominant $\mathrm{AD}$. The apolipoprotein $\mathrm{E}(A P O E) \mathrm{E} 4$ allele has also been identified as a risk factor for late onset AD [3]. Although all participants had typical AD hypometabolic patterns in their pre-operative PET scans, it is also possible that some of the younger participants did not have AD at all or had competing diseases that affected their clinical outcome and disease trajectories. Beyond genetic subtypes that affect the course of early onset AD, Schneider and colleagues [4] have also suggested that older participants with probable AD might have non-Alzheimer neuropathology (e.g., vascular disease, hippocampal sclerosis, TDP-43 proteinopathy) and/or decline more slowly than younger participants because of survival bias by which more rapidly declining individuals have progressed to a point where they are no longer eligible for the studies.

Several limitations related to this report must be noted. First, this was a post-hoc analysis of a defined sub-group within the ITT population and does not change the fact that the overall study did not reveal notable differences between the DBS-f "on" and "off" groups on any clinical metrics. We did not anticipate an over-representation of early onset AD when the protocol was written, and therefore did not specify age stratification in the initial statistical analysis plan. Second, ADvance was an exploratory phase II feasibility trial that intentionally allowed a wide age range and did not require ApoE or CSF biomarkers for eligibility. Although we confirmed that all enrolled patients had evidence of temporal-parietal hypometabolism prior to randomization, we cannot affirm that study participants had specific biomarkers consistent with probable AD. Third, the study sample was very small and not powered for statistical significance on any of the clinical metrics. Consequently, the post-hoc findings reported here must be interpreted with caution and require larger studies to address the clinical benefit that might be accrued by DBS-f treatment in mild AD.

These results highlight the importance of subject selection in clinical trials and the potential confounding effect that heterogeneous study populations can have on study outcomes. In this study, the recruitment of a disproportionately high number of younger $\mathrm{AD}$ participants adversely affected the outcome. In retrospect, it is not possible to determine whether other $\mathrm{AD}$ studies have failed because the candidate treatment intervention was ineffective and/or because the enrolled study population was too heterogeneous to detect a significant clinical effect (signal detection) in a sensitive (responsive) subtype. Patient recruitment is a challenge in all clinical trials and was a particular challenge in this study that required that the potential participant with mild $\mathrm{AD}$ consent to neurosurgery with the support and signed consent of a family member [35]. The recruitment challenges for this type of study were recently reported by Fontaine et al. [36] who noted that enrollment into a European DBS clinical trial for AD was extremely difficult. In that study, only 9 of 110 AD participants met study eligibility criteria and only one patient actually consented to participate in the neurosurgical procedure [36]. The screen failure rate of approximately $50 \%$ in the present study was consistent with most AD studies and, in that regard, was more successful than the European DBS study.

Despite several innovative strategies and more than $1000 \mathrm{AD}$ clinical trials in the past two decades, no new treatments have been approved since 2003 [35, 37-39]. During this same time, investigators have differentiated clinical, genetic, and neuropathological subtypes of $\mathrm{AD}$ and recognized multiple competing diseases subsumed within the so-called AD population that might obscure the interpretation of clinical trial results $[3,5,31-33,39-49]$. The lack of successful trials may be due, in part, to the heterogeneous populations of probable AD participants who were enrolled some of these studies. In a recent review, Ferreira and colleagues [5] emphasized that differentiation of the heterogeneity that exists within the $\mathrm{AD}$ population is critical for implementing precision medicine approaches and for ultimately developing successful treatments for AD. The findings from the ADvance study reinforce the importance of heterogeneity within $\mathrm{AD}$ and suggest that more restricted age limits, genotyping, and CSF biomarkers need to be part of the eligibility criteria for future AD trials.

\section{ACKNOWLEDGMENTS}

This research was supported by a grant from the National Institute on Aging, R01AG042165, and a 
vendor grant from Functional Neuromodulation Inc., the sponsor of the ADvance study.

The ADvance Study team including Todd Langevin, Lisa Fosdick, Kristen Drake, Donald E. Reymers, Robyn Moxon, Dan O'Connell, Susan Klees, Steven D. Targum, MD, and the seven participating clinical trial sites:

Chair's Office at Johns Hopkins University and University of Toronto: Constantine G. Lyketsos, MD, MHS, Co-Principal Investigator, Elizabeth Plank Althouse Professor and Chair of Psychiatry at Johns Hopkins Bayview; Andres Lozano, MD, $\mathrm{PhD}$, FRCSC, FACS, Co-Principal Investigator, Prof. and Chair of Neurosurgery, Tasker Chair of Functional Neurosurgery; Gwenn Smith, PhD, Imaging Core Director, Professor of Psychiatry and Behavioral Sciences, Johns Hopkins University; Cynthia Munro, PhD, Neuropsychologist, Associate Professor of Psychiatry and Behavioral Sciences, Johns Hopkins University; Esther Oh, MD, PhD, Medical Monitor, Assistant Professor of Geriatric Medicine, Johns Hopkins University; Jeannie Sheppard Leoutsakos, PhD, Data Core Leader, Assistant Professor of Psychiatry and Behavioral Sciences, Johns Hopkins University

Johns Hopkins University Memory and Alzheimer's Treatment Center and Alzheimer's Disease Research Center: Paul B. Rosenberg, MD, Assoc. Professor, Professor of Psychiatry and Behavioral Sciences; W. Stan Anderson MD, Assoc. Professor of Neurosurgery

Banner Alzheimer's Institute, Phoenix: Anna Burke, MD, currently Chair for Dementia, Director of Neuropsychiatry, and Director of Memory Disorders division at Barrow Neurological Institute; Francisco Ponce, $\mathrm{MD} / \mathrm{PhD}$, Associate Professor of Neurosurgery, Barrow

Banner Sun Health Research Institute, Phoenix: Marwan Sabbagh, MD, Director, Banner Sun Health Research Institute (currently Director of Translational Research, Cleveland Clinic Lou Ruvo Center for Brain Health; Francisco Ponce, MD/PhD, Associate Professor of Neurosurgery, Barrow

University of Toronto/Toronto Western Hospital: Andres Lozano, MD, PhD, FRCSC, FACS, Prof. of Neurosurgery, Tasker Chair of Functional Neurosurgery; David Tang-Wai, MDCM, Assist. Professor of Neurology

Brown University; Rhode Island Hospital, Butler Hospital: Stephen Salloway, MD, Professor of Neurology, Director of Neurology and Memory and Aging Program; Rees Cosgrove, MD/PhD, Chair of
Neurosurgery; Wael Asaad MD, PhD. Associate Professor of Neurosurgery and Neuroscience

University of Florida - Gainesville: Michael S. Okun, MD, Chair and Professor of Neurology,

Executive Director of the Norman Fixel Institute for Neurological Diseases; Kelly Foote, MD, Associate Professor of Neurosurgery

University of Pennsylvania: David Wolk, MD, Associate Professor of Neurology, Assistant Director Penn Memory Center; Gordon Baltuch, MD, Associate Professor of Neurosurgery

NAMSA for statistical assistance: Jill Shafer

Authors' disclosures available online (https:// www.j-alz.com/manuscript-disclosures/21-0530r1).

\section{REFERENCES}

[1] Kim EJ, Cho SS, Jeong Y, Park KC, Kang SJ, Kang E, Kim SE, Lee KH, Na DL (2005) Glucose metabolism in early onset versus late onset Alzheimer's disease: An SPM analysis of 120 participants. Brain 128, 1790-1801.

[2] van der Vlies AE, Koedam EL, Pijnenburg YA, Twisk JW, Scheltens P, van der Flier WM (2009) Most rapid cognitive decline in APOE e4 negative Alzheimer's disease with early onset. Psychol Med 39, 1907-1911.

[3] Bagyinszky E, Chul Young Y, An SSA, Kim SY (2014) The genetics of Alzheimer's disease. Clin Interv Aging $\mathbf{9}$, 535-551.

[4] Schneider LS, Kennedy RE, Wang G, Cutter GR (2015) Differences in Alzheimer disease clinical trial outcomes based on age of the participants. Neurology 84, 1121-1127.

[5] Ferreira D, Nordborg A, Westman E (2020) Biological subtypes of Alzheimer disease: A systematic review and meta-analysis. Neurology 94, 436-448.

[6] Lozano AM, Fosdick L, Chakravarty MM, Leoutsakos JM, Munro C, Oh E, Drake KE, Lyman CH, Rosenberg PB, Anderson WS, Tang-Wai DF, Pendergrass JC, Salloway S, Asaad WF, Ponce FA, Burke A, Sabbagh M, Wolk DA, Baltuch G, Okun MS, Foote KD, McAndrews MP, Giacobbe P, Targum SD, Lyketsos CG, Smith GS (2016) A phase II study of fornix deep brain stimulation in mild Alzheimer's disease. J Alzheimers Dis 54, 777-787.

[7] Laxton AW, Tang-Wai DF, McAndrews MP, Zumsteg D, Wennberg R, Keren R, Wherrett J, Naglie G, Hamani C, Smith GS, Lozano AM (2010) A phase I trial of deep brain stimulation of memory circuits in Alzheimer's disease. Ann Neurol 68, 521-534.

[8] Mielke MM, Okonkwo OC, Oishi K, Mori S, Tighe S, Miller MI, Ceritoglu C, Brown T, Albert M, Lyketsos CG (2012) Fornix integrity and hippocampal volume predict memory decline and progression to AD. Alzheimers Dement $\mathbf{8}$, 105-113.

[9] Hardenacke, K., Shubina E, Buhrle CP, Zapf A, Lenartz D, Klosterkotter J, Visser-Vandewalle V, Kuhn J (2013) Deep brain stimulation as a tool for improving cognitive functioning in Alzheimer's dementia: A systematic review. Front Psychiatry 4, 159.

[10] Buckner RL, Sepulcre J, Talukdar T, Krienen FM, Liu H, Hedden T, Andrews-Hanna JR, Sperling RA, Johnson RA (2009) Cortical hubs revealed by intrinsic functional 
connectivity: Mapping, assessment of stability, and relation to Alzheimer's disease. J Neurosci 29, 1860-1873.

[11] Seeley WW, Crawford RK, Zhou J, Miller BL, Greicius MD (2009) Neurodegenerative diseases target large-scale human brain networks. Neuron 62, 42-52.

[12] Lyketsos CG, Targum SD, Pendergrass JC, Lozano AM (2012) Deep brain stimulation: A novel strategy for treating Alzheimer's disease. Innov Clin Neurosci 9, 10-17.

[13] Smith GS, Laxton AW, Tang-Wai DF, McAndrews MP, Diaconescu AO, Workman CI, Lozano AM (2012) Increased cerebral metabolism after 1 year of deep brain stimulation in Alzheimer disease. Arch Neurol 69, 1141-1148.

[14] Rosen WG, Mohs RC, Davis KL (1984) A new rating scale for Alzheimer's disease. Am J Psychiatry 141, 1356-1364.

[15] Berg L (1988) Clinical dementia rating (CDR). Psychopharmacol Bull 24, 637-639.

[16] Hebert LE, Weuve J, Scherr PA, Evans DA (2013) Alzheimer disease in the United States (2010-2050) estimated using the 2010 census. Neurology 80, 1778-1783.

[17] Alzheimer's Association (2019) Alzheimer's disease 2019: Facts and figures. Alzheimers Dement 15, 321-387.

[18] Ponce FA, Asaad W, Foote KD, Anderson WS Cosgrove GR Baltuch GH, Beasley K, Fosdick L, Oh ES, Targum SD, Smith GS, Lyketsos, CG, Lozano AM (2016) Bilateral deep brain stimulation of the fornix for Alzheimer's disease: Surgical safety in the ADvance Trial. $J$ Neurosurgery $\mathbf{1 2 5}$, 75-84.

[19] Leoutsakos JS, Yan H, Anderson WS, Asaad WF, Baltuch G, Burke A, Chakravarty MM, Drake KE, Foote KD, Fosdick L, Giacobbe P, Mari Z, McAndrews MP, Munro CA, Oh ES, Okun MS, Pendergrass JC, Ponce FA, Rosenberg PB, Sabbagh MN, Salloway S, Tang-Wai DF, Targum SD, Wolk D, Lozano AM, Smith GS, Lyketsos CG (2018) Deep brain stimulation targeting the fornix for mild Alzheimer dementia (the ADvance Trial): A two year follow-up including results of delayed activation. J Alzheimers Dis 64, 597-606.

[20] Galasko D, Schmitt F, Thomas R, Jin S, Bennett D, Alzheimer's Disease Cooperative Study (2005) Detailed assessment of activities of daily living in moderate to severe Alzheimer's disease. J Int Neuropsychol Soc 11, 446-453.

[21] Wessels AM, Siemers ER, Yu P, Andersen SW, Holdridge KC, Sims JR, Sundell K, Stern Y, Rentz DM, Dubois B, Jones RW, Cummings J, Aisen PS (2015) A combined measure of cognition and function for clinical trials: The Integrated Alzheimer's Disease Rating Scale (iADRS). $J$ Prev Alzheimers Dis 2, 227-241.

[22] Wessels AM, Andersen SW, Dowsett SA, Siemers ER (2018) The Integrated Alzheimer's Disease Rating Scale (iADRS): Findings from the EXPEDITION3 Trial. $J$ Prev Alzheimers Dis 5, 134-136.

[23] Mintun MA, Lo AC, Duggan CE, Wessels AM, Ardayfio PA, Andersen SW, Shcherbinin S, Sparks JD, Sims JR, Brys M, Apostolova LG, Salloway SP, Skovronsky DM (2021) Donanemab in early Alzheimer's disease. N Eng J Med 384, 1691-1704.

[24] McKhann GM, Knopman DS, Chertkow H, Hyman BT, Jack CR, Kawas CH, Klunk WE, Koroshetz WJ, Manly JJ, Mayeux R, Mohs RC, Morris JC, Rossor MN, Scheltens P, Carrillo MC, Thies B, Weintraub S, Phelps C (2011) The diagnosis of dementia due to Alzheimer's disease: Recommendations from the National Institute on Aging-Alzheimer's Association workgroups on diagnostic guidelines for Alzheimer's disease. Alzheimers Dement 7, 263-269.

[25] Morris JC (1997) Clinical dementia rating: A reliable and valid diagnostic and staging measure for dementia of the Alzheimer type. Int Psychogeriatr 9(Suppl 1), 173-176; discussion 177-178.

[26] Young RC, Biggs, JT, Ziegler VE, Meyer DA (1978) A rating scale for mania: Reliability, validity, and sensitivity. Brit J Psychiatry 133, 429-435.

[27] Alexopoulos GS, Abrams RC, Young RC, Shamoian CA (1988) Cornell scale for depression in dementia. Biol Psychiatry 23, 271-284.

[28] Cummings JL, Mega M, Gray K, Rosenberg-Thompson S, Carusi DA, Gornbein J (1994) The neuropsychiatric inventory: Comprehensive assessment of psychopathology in dementia. Neurology 44, 2308-2314.

[29] Posner K, Brown GK, Stanley B, Brent DA, Yershova KV, Oquendo MA, Currier GW, Melvin GA, Greenhill L, Shen S, Mann JJ (2011) The Columbia-Suicide Severity Rating Scale: Initial validity and internal consistency findings from three multisite studies with adolescents and adults. Am J Psychiatry 168, 1266-1277.

[30] Holroyd KB, Fosdick L, Smith G, Leoutsakos JM, Munro C, Oh E, Drake K, Rosenberg PB, Anderson WS, Salloway S, Pendergrass C, Burke A, Wolk DA, Tang-Wai DF, Ponce FA, Asaad WF, Sabbagh M, Okun MS, Baltuch G, Foote KD, Targum S, Lozano AM, Lyketsos CG (2015) Deep brain stimulation targeting fornix for mild Alzheimer Dementia: Design of the ADvance randomized controlled trial. Open Access J Clin Trials 7, 63-76.

[31] Lakens D (2013) Calculating and reporting effect sizes to facilitate cumulative science: A practical primer for $t$-tests and ANOVAs. Front Psychol 4, 863.

[32] Komarova N, Thalhauser C (2011) High degree of heterogeneity in Alzheimer's progression patterns. PLoS Comput Biol 7, e1002251.

[33] Kelleher RJ, Shen J (2017) Presenilin-1 mutations and Alzheimer's disease. Proc Natl Acad Sci U S A 114, 629-631.

[34] Lo M-T, Kauppi K, Fan C-C, Sanyal N, Reas ET, Sundar VS, Lee W-C, Desikan RS, McEvoy LK, Chen C-H (2019) Identification of genetic heterogeneity of Alzheimer's disease across age. Neurobiol Aging 84, 243.e1-243.e9.

[35] Vellas, B, Hampel H, Rouge-Bugat ME, Grundman M, Andrieu S, Abu-Shakra S, Bateman R, Berman R, Black R, Carillo M, Donohue M, Mintun M, Morris J, Petersen R, Thomas RG, Suhy J, Schneider L, Seely L, Tariot P, Touchon J, Weiner M, Sampaio C, Aisen P (2012) Task Force Participants: Alzheimer's disease therapeutic trials: EU/US Task Force report on recruitment, retention, and methodology. Nutr Health Aging 16, 339-345.

[36] Fontaine D, Deudon A, Lemaire JJ, Razzouk M, Viau P, Darcourt J, Robert P (2013) Symptomatic treatment of memory decline in Alzheimer's disease by deep brain stimulation: A feasibility study. J Alzheimers Dis 34, 315-323.

[37] Ousset PJ, Cummings J, Delrieu J, Legrand V, Prins N, Winblad B, Touchon J, Weiner MW, Vellas B (2014) Is Alzheimer's disease drug development broken? What must be improved. J Prevention Alzheimers Dis 1, 40-45.

[38] Prince M, Wimo A, Guerchet M, Ali G, Wu YT, Prina M (2015) World Alzheimer Report 2015. The global impact of dementia: An analysis of prevalence, incidence, cost and trends. Alzheimer's Disease International, London.

[39] Cummings J, Lee G, Ritter A, Sabbagh M, Zhong K (2019) Alzheimer's disease drug development pipeline. Alzheimers Dement (N Y) 5, 272-293. 
[40] Iqbal A, Grundke-Iqbal I (2010) Alzheimer disease, a multifactorial disorder seeking multi-therapies. Alzheimers Dement 65, 420-424.

[41] Ringman JM, Goate A, Master CL, Cairns NJ, Danek A, Graff-Radford N, Ghetti B, Morris JC (2014) Genetic heterogeneity in Alzheimer disease and implications for treatment strategies. Curr Neurol Neurosci Rep 14, 499.

[42] Ossenkoppele R, Schonhaut D, Scholl M, Lockhart SN, Ayakta N, Baker SL, O'Neil JP, Janabi M, Lazaris A, Cantwell A, Vogel J, Santos M, Miller ZA, Bettcher BM, Vossel KA, Kramer JH, Gorno-Tempini ML, Miller BL, Jagust WJ, Rabinovici GD (2016) Tau PET patterns mirror clinical and neuroanatomical variability in Alzheimer's disease. Brain 139, 1551-1567.

[43] Ferreira D, Verhagen C, Hernandez-Cabrera J, Cavallin L, Guo CJ, Ekman U, Muehlboeck JS, Simmons A, Barroso J, Wahlund LO, Westman E (2017) Distinct subtypes of Alzheimer's disease based on patterns of brain atrophy: Longitudinal trajectories and clinical applications. Sci Rep 7, 46263.

[44] Scheltens NME, Tijms BM, Koene T, Barkhof F, Teunissen CE, Wolfsgruber S, Wagner M, Kornhuber J, Peters O, Cohn-Sheehy BI, Rabinovici GD, Miller BM, Kramer JH, Scheltens P, van der Flier WM (2017) Cognitive subtypes of probable Alzheimer's disease robustly identified in four cohorts. Alzheimers Dement 13, 1226-1236.
[45] Devi G, Scheltens P (2018) Heterogeneity of Alzheimer's disease: Consequence for drug trials? Alzheimers Res Ther 10, 122

[46] Yashin AI, Fang F, Kovtun M, Wu D, Duan M, Arbeev K, Akushevich I, Kulminski A, Culminskaya I, Zhbannikov I, Yashkin A, Stallard E, Ukraintseva S (2018) Hidden heterogeneity in Alzheimer's disease: Insights from genetic association studies and other analyses. Exp Gerontol 107, 148-160.

[47] Power MC, Mormino E, Soldan A, James BD, Yu L, Armstrong NM, Bangen KJ, Delano-Wood L, Lamar M, Lim YY, Nudelman K, Zahodne L, Gross AL, Mungas D, Widaman KF, Schneider J (2018) Combined neuropathological pathways account for age-related risk of dementia. Ann Neurol 84, 10-22.

[48] Belloy ME, Napolioni V, Greicius MD (2019) A quarter century of APOE and Alzheimer's disease: Progress to date and the path forward. Neuron 101, 820-838.

[49] Badwar A, McFall GP, Sapkota S, Black SE, Chertkow H, Duchesne S, Masellis M, Li L, Dixon RA, Bellec P (2020) A multiomics approach to heterogeneity in Alzheimer's disease: Focused review and roadmap. Brain 143, 1315-1331. 